\title{
Research in Technology Education: looking back to move forward again
}

\author{
P John Williams \\ Technology, Environment, Mathematics and Science Education Research Centre \\ University of Waikato, New Zealand
}

\section{Introduction}

In 2013 I published, in this Journal, a review of journals and conference publications in Technology Education from 2006 to 2010 as one measure of the nature of research that was being conducted in the area (Williams, 2013). An element of that review was a prediction of trends, from the findings, to speculate about what research areas may develop and become more significant and more common in the future. This prediction was integrated with personal experiences and understandings to result in a speculative discussion of future trends.

This Research Note represents an extended review, both in terms of the journals and conferences covered, and the time period to include 2011-2013, in order to evaluate those predictions and refine possible future trends, and to answer the research question: What are the developments and trends in Technology Education research? It is hoped that this will be useful to researchers in the area of Technology Education who are planning research, and to stimulate discussion about the research that is needed in this area.

\section{Review Method}

In the 2006-2010 study (Williams, 2013) I analysed research that had been published in three journals and presented each year at four conferences. The journals were:

1. The Journal of Technology Education, edited in the US and published in paper form and freely available on the Virginia Tech website,

2. the International Journal of Technology and Design Education, published by Kluwer in the Netherlands, available by subscription in paper and online, and

3. Design and Technology Education: an International Journal (journal of the professional association in the UK, available freely to association members in paper and online.

The four conferences reviewed were the:

1. annual UK Design and Technology Association conference,

2. PATT conferences which occasionally have more than one in a year,

3. biannual Technology Education New Zealand professional association conference,

4. biannual Technology Education Research Conference (TERC) sponsored by Griffith University in Australia.

This analysis resulted in 472 manuscripts which were either published or presented.

In addition to these sources, for the 2011-2013 period, I added the Journal of Technology Studies (the journal of the Epsilon pi Tau professional technology fraternity in the United States), the biannual Asia-Pacific International Conference on Technology Education (ICTE), and the Council for Technology and Engineering Teacher Education (CTETE) conference, which is run in the United States each year in conjunction with the ITEEA conference. The UK Design and Technology Association conference was not included in the 2011-13 period because there have been minimal research papers presented at this conference. This added another 713 manuscripts to the 472 that had been analysed previously for a total of 1187 .

The methodology of sample selection for this analysis was admittedly somewhat idiosyncratic, and this represents a limitation of the findings. Within those limitations, the research approach was inclusive, and so considered papers which were clearly and identifiably research, posing an empirical 
question and using quantitative or qualitative methods, but also papers which were more theoretical position papers, retrospective analyses and presentations of practice. The rationale for this broad approach was that it would provide a more representative indication of academic pursuit within the community of technology educators.

A matrix was developed to represent each of the ten sources of research and what developed into twenty-seven topic areas covered over the eight year period. The topic areas were developed initially for the 2006 - 2010 study through an inductive process of development, which was not predetermined and allowed for flexibility (Braun \& Clarke, 2006). As the source papers were scanned, they were allocated to a topic. A refinement process was utilized initially involving some reallocation and coding adjustment, until a stable situation was achieved in which each new paper clearly fitted to an existing topic. Some papers could be coded based on the title, some required a review of the abstract, and others had to be read more thoroughly in order to classify according to topic. Each paper was coded only in one topic, so in some instances a judgement was made about the main focus of the paper.

\section{Findings}

The most productive source of research papers was the PATT conferences (338 papers) because of their frequency, for example there were two conferences in many years during this period, one each year in conjunction with the International Technology Education Association Conference in the USA, and one in another country. Fortunately now, most of the PATT conference proceedings are available through the International Technology Education Association website

(http://www.iteea.org/Conference/pattproceedings.htm). The most productive of the four journals was the International Journal of Technology and Design Education (208 papers). This is the only technology education journal consistently cited in international lists of 'High Impact Journals' and so has a significant status within the profession.

The most common research topics to be covered in the journals over this period (2006-2013) are mostly explicable:

- Journal of Technology Education: the fact that STEM topics were covered most frequently (16\%, same as 2006-2010) is not surprising given the emphasis that is being applied to STEM initiatives in the USA.

- International Journal of Technology and Design Education: the most frequently published research topic was around sustainability/environmental issues in technology education in 2006-10 (10\%), and is around learning in 2006-13 (10\%).

- Design and Technology Education: an International Journal most frequently published research related to design (10\% in 2006-10 to 13\% in 2006-13); not surprising in a curriculum context where the school subject in England is called Design and Technology.

- Journal of Technology Studies most common publication topic (2011-2013) was related to mobile and online learning (15\%).

Technological literacy was the most frequently (16\% in 2006-10, 8\% in 2006-13) presented topic at the PATT conferences, and research about values and beliefs in technology education was most commonly presented at the TERC conferences (20\% in 2006-10 and 14\% in 2006-13). While in 200610 there was no specific topic which most frequent at the New Zealand professional association conferences (TENZ), in 2006-13 curriculum was the theme most frequently presented (17\%). At the ICTE (Asia-Pacific) conference, 13\% of presentations were focussed on the technology education system of an identified country, closely followed by $12 \%$ of presentations about the curriculum. The topic of STEM was the most commonly presented (32\%) at the US based CTETE conferences in the 2011-13 period. 
It was significant that no single topic had an outstandingly high frequency of papers, so a broad spread of research interest within the profession was represented. A meta-analysis indicated that the most common topic across all conferences and journals in the 2006-10 period was design (9\%). In the 2006-13 period the most common topic was related to curriculum (9\%) which covered a range of subtopics including technology curriculum content, industry links, engineering in the curriculum, development and implementation, country analyses, indigenous technologies and related to specific areas (for example, food) or projects (for example, robotics).

After curriculum, in order of frequency, the following topics were the focus of research papers over the 2006-13 period:

i) Design (8\%) included the conceptual foundations of design and other theoretical perspectives, analysis of pupils design decisions, exemplars of and correlations between design practice in school and in industry, design teams, designing and teaching styles and elements of student design.

ii) STEM (7\%) included professional development, instructional methods, standards for technological literacy applied to STEM, and generating interest in STEM.

iii) Teaching (6\%) topics include the use of physical modelling, problem-based learning, teaching through design, metaphor and pedagogy, and the constituents of effective teaching

iv) Learning (6\%) transfer of learning, project and problem based learning, learning outcomes, self directed learning and motivation to learn.

The above summary is for the 8 year period of 2006-13. Breaking this information down into the two periods of analysis 2006-10 and 2011-13 provides an indicator of how the focus of research has changed over time. Table 1 indicates the frequency of research topics over the 2006-10 period, which is the same as was reported in 2013 (Williams, 2013).

Table 1. Frequency of research topics, 2006-10.

\begin{tabular}{|c|c|l|}
\hline Rank & no & Topic \\
\hline 1 & 42 & Design \\
\hline 23 & 34 & Curriculum \\
\hline 23 & 34 & Tech Literacy \\
\hline 4 & 32 & Thinking \\
\hline 567 & 29 & Teaching \\
\hline 567 & 29 & PATT \\
\hline 567 & 29 & Teacher training \\
\hline 8 & 27 & Learning \\
\hline 9 & 25 & Values/beliefs \\
\hline 10 & 22 & Sustainability/environ \\
\hline
\end{tabular}

It was noted at the time that it seemed that the scope of research in technology education during this period was broader than in the past. The inclusion of conference papers in this review has essentially broadened the scope of research further by including researchers from more countries, and consequently comparisons with past reviews must be made with caution. But a possible alternative interpretation was that the profession is developing a level of research maturity which is reflected in the diversity of topics. As technology education has become a more securely situated component of school education, a preoccupation with the curriculum seems less necessary, and has been overcome to enable researchers to broaden their agenda. However to a certain extent, the research tendency to focus on curriculum continues, with papers in this category being the second most frequent in this review. 
Table 2 represents the most frequent topics of research during the period 2011-13, from the extended sources of four journals and six conferences.

Table 2. Frequency of research topics, 20011-13.

\begin{tabular}{|c|c|l|}
\hline Rank & no & Topic \\
\hline 1 & 55 & STEM \\
\hline 2 & 53 & Curriculum \\
\hline 3 & 44 & Design \\
\hline 4 & 41 & Learning \\
\hline 5 & 40 & Teaching \\
\hline 6 & 33 & Teacher training \\
\hline 7 & 29 & ICT \\
\hline 8 & 23 & Thinking \\
\hline 910 & 19 & PATT \\
\hline 910 & 19 & Sustainability/environ \\
\hline
\end{tabular}

With four exceptions, the top ten topics for the 2006-10 period and the 2011-13 period are the same: the exceptions are the area of values and beliefs and technological literacy which are out of the top 10 , and STEM and ICT which are now in the top ten. Table 3 indicates the most significant changes in the rank of topics between these two periods. As stated, this comparison must be analysed with caution, because the 2011-13 period included some sources that were not included in the original timeframe: the US based Journal of Technology Studies (JTS), the Asian based International Conference of Technology Education (ICTE) and the US Council of Technology and Engineering Teacher Educators (CTETE). For example the CTETE conference included 32\% of papers on the topic of STEM, and this focus is influential in the dominance of STEM as an overall area of research

Table 3. Rank change of research topics, 2006-10 and 2011-13.

\begin{tabular}{|l|l|}
\hline \multicolumn{2}{|l|}{ 2006-2010 compared with 2011-2013 } \\
\hline Area & Rank change \\
\hline LESS COMMON & 2.5 to 12.5 \\
\hline Tech Literacy & 4 to 8 \\
\hline Thinking & 9 to 23 \\
\hline Values / beliefs & \\
\hline & \\
\hline MORE COMMON & 12.5 to 1 \\
\hline STEM & 8 to 4 \\
\hline Learning & 20 to 7 \\
\hline ICT & \\
\hline
\end{tabular}

Tables 4 and 5 compare the 2006-2010 period with the overlapping data for the broader and encompassing period of 2006-2013, whereas the above Tables 2 and 3 compare the two separate periods of time 2006-10 and 2011-13. Tables 4 and 5 therefore provide for a more indicative trend, as the latter period builds on to the earlier period of the previous study.

Table 4. Comparative ranks of research topics.

\begin{tabular}{|c|c|c|c|c|c|}
\hline \multicolumn{2}{|c|}{$2006-2013$} & \multicolumn{2}{|c|}{$2006-2010$} & \\
\hline no & \multicolumn{2}{|c|}{ Rank } & no & Topic \\
\hline 89 & 2 & 1 & 42 & Design \\
\hline
\end{tabular}




\begin{tabular}{|c|c|c|l|l|}
\hline 111 & 1 & 23 & 34 & Curriculum \\
\hline 53 & 910 & 23 & 34 & Tech Literacy \\
\hline 63 & 8 & 4 & 32 & Thinking \\
\hline 75 & 4 & 567 & 29 & Teaching \\
\hline 53 & 910 & 567 & 29 & PATT \\
\hline 64 & 7 & 567 & 29 & Teacher training \\
\hline 73 & 5 & 8 & 27 & Learning \\
\hline 35 & 15 & 9 & 25 & Values/beliefs \\
\hline 66 & 6 & 10 & 22 & Sustainability/environ \\
\hline 80 & 3 & 1213 & 18 & STEM \\
\hline
\end{tabular}

Table 5. Rank change of research topics, 2006-10 and 2006-13.

\begin{tabular}{|l|c|}
\hline \multicolumn{2}{|l|}{$2006-2010$ compared with 2006-2013 } \\
\hline Area & Rank change \\
\hline LESS COMMON & 2.5 to 9.5 \\
\hline Tech literacy & 4 to 8 \\
\hline Thinking & 6 to 9.5 \\
\hline PATT & 9 to 15 \\
\hline Values / beliefs & \\
\hline & \\
\hline MORE COMMON & 8 to 5 \\
\hline Learning & 10 to 6 \\
\hline Sustainability/environs & 12.5 to 3 \\
\hline STEM & 20 to 11 \\
\hline ICT & 14 to 12 \\
\hline Mobile/online
\end{tabular}

The four areas that have become less common over the total period, in order of greatest rank difference are Technological Literacy, Values/beliefs, Thinking and PATT. Even though overall research related to Technological Literacy has declined over this period, it is still the most common category of papers presented at the PATT conferences. Similarly with research related to values and beliefs, while declining overall, it is the most commonly presented topic at TERC conferences.

The five areas that have become more common over the total period, in order of greatest rank difference are STEM, ICT, Sustainability/environmental, Learning and Mobile/online. The US contribution to the prominence of STEM related research is significant, as it is the most commonly represented topic in both the Journal of Technology Education and the Council for Technology and Engineering Teacher Education conference. Research focussed on Learning and Sustainability/environmental issues are the first and second most common topics covered by articles in the International Journal of Technology and Design Education.

\section{Research Trends}

It is a fraught exercise to try and predict future trends, but on the basis of this study compared with the previous study (Williams, 2013) there are some directions indicated which can be discussed in terms of technology education research in the future.

Based in the analysis of the 2006-2010 data, the following comment was made: 
The most frequent topics of research cited in this review will continue. They have been identified as common in previous reviews of research, and are like the 'bread and butter' of technology education research; these include design, curriculum and technological literacy. (Williams, 2013, p. 5).

This current research supports the notion that research into areas of Design and Curriculum have continued, and will continue to dominate research in technology education. Technological Literacy is a less common area of research than in the past, though it is still the most commonly presented topic at the PATT conferences. The additional sources of data considered for the 2011-2013 period (JTS, ICTE and CTETE) do not include a high level of research in Technological Literacy, and so would be partly responsible for the less frequent ranking of this topic. However, it could also be the case that there is a feeling that Technological Literacy is now well established as a significant goal of Technology Education and so the research imperative is less.

It was noted in 2013 that:

The next most frequent topic will also continue to be prominent, thinking, because it reflects a professional awareness that understanding about how students think and learn is pivotal to successful technology education programs (Williams, p. 5).

While the area of Thinking has slipped a few ranks (4 to 8) over this period, I think the rationale stated here remains applicable and there is a continuing need for this research into the future. Table 4 indicates that the ranks of the areas of Thinking and Learning have almost swapped with each other in these time periods. This could indicate a shift in research priority, and a recognition that an understanding of how students learn in technology is fundamental. This aligns well with the conclusions of international experts developed by Ritz and Martin (2013) in that the five most important issues requiring research included:

- understanding the learning that takes place through the technology curriculum,

- technological conceptual knowledge, and

- How students learn in technology education. (p 780)

It also continues the finding from Johnson and Dougherty's 2008 study that one of the two most common foci of the 199 articles they examined between 1997 - 2007 was learning.

The area of STEM research changed rankings (12.5 to 3) more than any other area in this time period, a trend that was predicted in 2013:

... I suspect this area of research will become more frequent as the STEM agenda, particularly in the USA, UK and to a lesser extent in other countries, becomes more politically embedded in policy and also in research funding criteria (Williams, 2013, p. 5)

While the focus on STEM continues to gain prominence in many countries, the research in this area is driven by the US. The two largely US based sources of data considered in this study: the Journal of Technology Education and the Council for Technology and Engineering Teacher Education conference, both have STEM related papers as the most common area of publication. There is no indication that this trend will abate in the US, and as it continues to gain momentum in other countries, it is likely that it will remain a significant area of research activity in technology education. The following 2013 observation remains relevant:

Research is certainly needed in this area in which education institutions are progressing a STEM alignment in the absence of a sound learning rationale and tested models of effective practice that integrates these subjects (Williams, 2013, p. 5). 
STEM research is an interesting case of a political rather than an education agenda and rationale, and often research funding will follow political developments. So researchers engage in this research because the funding is there, rather than necessarily being driven by educational need.

The 2013 Horizon Report (Johnson, Adams Becker, Cummins, Estrada, Freeman \& Ludgate, 2013) identified and described emerging technologies, and the likely timeframes for their entrance into mainstream use for teaching, learning and creative inquiry. Cloud computing and mobile learning were identified to enter into the mainstream within the next year. How these developments could impact on technology education is increasingly being researched (mobile/online research was ranked $14^{\text {th }}$ and now $12^{\text {th }}$ in this review, ICT moved from a rank of 20 to 11) and will continue through enquiries into e-portfolios, mobile devices, web based systems, blended learning and digital assessment.

In 2013 it was predicted that:

The notion of Pedagogical Content Knowledge will be a topic which increasingly frames research about teaching because of its capacity to accommodate the complexity of variables that result in successful teaching. This will enable research to more accurately represent the complex reality of the classroom (Williams, p.5).

This current research has not confirmed this prediction to be the case, despite the alignment with Ritz and Martin's 2013 conclusion that an important issue requiring research is pedagogical content knowledge. Much of the PCK research which has conducted has been related to the content area of science. The principles that have subsequently been developed do not all necessarily apply to the teaching of technology (Williams \& Lockley, 2012), and this may have inhibited PCK research in technology to develop. Nevertheless, it seems that this will be an area of increasing research importance in the future.

Shifts in views of learning from a cognitive constructivist perspective to a more sociological view which considers the cultural context and interactions between people, should also impact on future research in technology education. Pedagogies to ensure students are active participants in the learning process, and the embedding of student design activities in a social context are aspects of technology education that need verification through research. This more social constructivist perspective aligns well with the essentially social manner in which technology is developed through design teams, for example, and so further supports a collaborative classroom environment in technology education.

In conclusion, the research trends in technology education include increasing research in STEM, information technologies, sustainability issues and mobile learning; and less research about technological literacy and values. The future trends for research in technology education will continue to be diverse, and increasingly so, in order to address the needs of this developing profession.

\section{References}

Braun, V., \& Clarke, V. (2006). Using thematic analysis in psychology. Qualitative Research in Psychology, 3(2), 77-101. doi:10.1191/1478088706qp063oa

Johnson, S. D., \& Daugherty, J. (2008). Quality and characteristics of recent research in Technology Education. Journal of Technology Education, 20(1), 16-31.

Johnson, L., Adams Becker, S., Cummins, M., Estrada, V., Freeman, A., and Ludgate, H. (2013). NMC Horizon Report: 2013 K-12 Edition. Austin, Texas: The New Media Consortium.

Ritz, J. \& Martin, G. (2013) Research needs for technology education: an international perspective. International Journal of Technology and Design Education, 23, 767-783. 
Skogh, I. \& M.J. de Vries, M.J. (Eds.) (2013) Technology Teachers as Researchers. The Netherlands: Sense Publishers

Williams, P.J. (2013) Research in Technology Education: looking back to move forward. International Journal of Technology and Design Education. 23(1), 1-9.

Williams, P.J. \& Lockley, J. (2012) An Analysis of PCK to elaborate the difference between Scientific and Technological Knowledge. Pupils Attitude Toward Technology (PATT) 26 Conference: Technology Education for the $21^{\text {st }}$ Century. Stockholm, June. 